\title{
Análisis inmunofenotípico de muestras normales de médula ósea: aplicaciones en el control de calidad en los laboratorios de citometría
}

\author{
Diana Carolina Roa-Higuera ${ }^{1}$, Susana Fiorentino ${ }^{2}$, Viviana Marcela Rodríguez-Pardo ${ }^{2}$, \\ Alba Myriam Campos-Arenas ${ }^{3}$, Elvira Antonia Infante-Acosta ${ }^{3}$, Claudia Cecilia Cardozo-Romero ${ }^{3}$, \\ Sandra Milena Quijano-Gómez ${ }^{1 *}$ \\ ${ }^{1}$ Facultad de Ciencias. Pontificia Universidad Javeriana, Bogotá, D.C. Colombia. \\ ${ }^{2}$ Grupo de Inmunobiología y Biología Celular. Departamento de Microbiología, Pontificia Universidad Javeriana, Bogotá, D.C. Colombia. \\ ${ }^{3}$ Laboratorio Clínico. Hospital Universitario San Ignacio. Bogotá, D.C. Colombia. \\ *squijano@javeriana.edu.co
}

Recibido: 06-10-2010; Aceptado: 09-11-2010

\begin{abstract}
Resumen
Objetivo. Describir un protocolo estandarizado mediante citometría de flujo para cuantificar en términos absolutos y relativos distintas subpoblaciones celulares de médula ósea normal y analizar la expresión de diferentes marcadores celulares específicos de linaje cuya reactividad está asociada a la diferenciación celular para ser usado como parte del control de calidad de rutina en los laboratorios de citometría. Materiales y métodos. El análisis inmunofenotípico de distintas subpoblaciones celulares se realizó en muestras de MO normal empleando un panel de anticuerpos monoclonales y policlonales útiles para la caracterización fenotípica de leucemias agudas en 4 fluorescencias distintas, con un protocolo que combina marcaje celular de antígenos de membrana y de citoplasma. El análisis de expresión se realizó en términos de intensidad media de fluorescencia. Para el cálculo de recuentos absolutos se adicionaron esferas fluorescentes de concentración conocida. Resultados. El panel de anticuerpos utilizado permitió la identificación y cuantificación de las distintas subpoblaciones leucocitarias normales de origen linfoide y mieloide incluyendo células precursoras CD34+, y poblaciones celulares más diferenciadas incluidas en las líneas granulocítica, monocítica y eritroide. Se establecieron los valores de referencia de las poblaciones celulares y los rangos de expresión de los diferentes marcadores celulares importantes como parte del control de calidad de rutina en los laboratorios de citometría. Conclusión. Los patrones inmunofenotípicos identificados y la determinación de los valores absolutos y relativos de referencia de las distintas poblaciones leucocitarias normales en MO podrán ser utilizados por los laboratorios de citometría como modelo para establecer parámetros de referencia en el análisis fenotípico de neoplasias hematológicas.
\end{abstract}

Palabras clave: citometría de flujo multiparamétrica, inmunofenotipo, neoplasias hematológicas, médula ósea normal, valores de referencia, control de calidad.

\begin{abstract}
Immunophenotypic analysis of normal cell samples from bone marrow: applications in quality control of cytometry laboratories. Objective. To describe a standardized flow cytometry protocol for the relative and absolute quantification of hematopoietic cell subpopulations from normal bone marrow, and to evaluate the expression of different lineage-specific cell markers with a reactivity associated to cell differentiation to be used as part of the routine quality control in cytometry laboratories. Materials and methods. The immunophenotypical analysis of different cell subpopulations was done with samples from normal bone marrow using a panel of monoclonal and polyclonal antibodies useful in the characterization of acute leukemias with four different fluorescences, by means of a protocol that combines cell labeling of membrane and cytoplasm antigens. Expression analysis was done in terms of mean fluorescence intensity (MFI). Fluorescent beads at a known concentration were added for calculating the absolute count of cells. Results. The antibody panel used allowed the identification and quantification of different normal leukocyte subpopulations of lymphatic and myeloid origin, including CD34+ stem cells
\end{abstract}


and more differentiated cell populations in the granulocytic, monocytic, and erythroid cell lines. We established reference values for cell populations and cell marker expression ranges as part of routine quality control of cytometry laboratories. Conclusion. Immunophenotypic patterns identified as well as absolute and relative reference values for the different normal leukocyte populations from bone marrow can be used by cytometry laboratories as a basis for establishing reference parameters in phenotypic analyses of hematologic neoplasia.

Key words: multiparametric flow cytometry, immunophenotype, hematologic neoplasia, normal bone marrow, reference values, quality control.

\section{Resumo}

Análise imunofenotípica de amostras de medula óssea normal: aplicações no controle de qualidade em laboratórios de citometria. Objetivo. Descrever um protocolo padronizado por citometria de fluxo para quantificar em termos absolutos e relativos diferentes subpopulações de células de medula óssea normal e analisar a expressão de diferentes marcadores celulares de linhagem específica, cuja reatividade é associada com a diferenciação celular para ser usado como parte do controle de qualidade de rotina nos laboratórios de citometria de fluxo. Materiais e métodos. A análise imunofenotípica das subpopulações de células foi realizada em amostras de MO normais utilizando um painel de anticorpos monoclonais e policlonais úteis para a caracterização fenotípica de leucemia aguda em quatro fluorescências, com um protocolo que combina rotulagem celular de antígeno de membrana celular e de citoplasma. A análise de expressão foi realizada em termos de intensidade média de fluorescência. Para calcular a recontagem absoluta foram adicionadas esferas fluorescentes de concentração conhecida. Resultados. O painel de anticorpos utilizado permitiu a identificação e quantificação das subpopulações de leucócitos normais de origem linfóide e mielóide incluindo as células precursoras CD34+, e populações de células mais diferenciadas incluídas nas linhas granulocítica, monocítica e eritróide. Foram estabelecidos os valores de referência das populações celulares e os intervalos de expressão dos diferentes marcadores celulares importantes como parte da rotina de controle de qualidade em laboratórios de citometria. Conclusão. Os padrões imunofenotípicos identificados e a determinação dos valores absolutos e relativos de referência das diferentes populações de leucócitos normais em MOM podem ser utilizados pelos laboratórios de citometria como um modelo para estabelecer parâmetros de referencia na análise fenotípica de neoplasias hematológicas.

Palavras-chave: citometria de fluxo multiparâmetro, imunofenótipo, neoplasias hematológicas, medula óssea normal, valores de referência, controle de qualidade.

\section{Introducción}

La hematopoyesis es un proceso complejo que tiene lugar en la médula ósea (MO), en donde una red de células estromales (nicho medular), citocinas y otros factores de crecimiento regulan la proliferación y diferenciación de células madre progenitoras dando lugar a los distintos tipos de células maduras circulantes en la sangre periférica y otros tejidos (eritrocitos, granulocitos, linfocitos monocitos y plaquetas) (1-6). La introducción de anticuerpos monoclonales en el estudio de la MO normal ha confirmado la gran heterogeneidad de los precursores hematopoyéticos y de los linajes derivados a partir de estas células, demostrando que los cambios morfológicos coexisten con distintos patrones de expresión inmunofenotípicos asociados a diferenciación celular (3).

Alteraciones clonales en la hematopoyesis como consecuencia de anormalidades genéticas recurrentes presentes en diferentes poblaciones celulares, pueden conducir al desarrollo de distintas patologías que cursan con sobreproducción de células hematopoyéticas (como las leucemias y linfomas), o con una producción deficiente de las mismas (anemias y síndromes mielodisplásicos) $(2-4,6)$.

Desde el punto de vista diagnóstico, el análisis inmunofenotípico de las células hematopoyéticas normales mediante citometría de flujo multiparamétrica (CMF), ha representado una herramienta fundamental para clasificar diferentes tipos de neoplasias derivadas de estas células $(3,7)$. En relación con las leucemias agudas y los síndromes mielodisplásicos (SMD), el estudio inmunofenotípico mediante CMF, está dirigido a la identificación de la línea celular implicada en el proceso de proliferación clonal y el estadio madurativo de la misma, empleando diferentes paneles de marcadores claramente establecidos por grupos expertos en citometría en el que se incluyen anticuerpos monoclonales y policlonales dirigidos frente a antígenos con diferentes especificidades para cada línea $(3,6,8)$. De esta manera, el análisis de la expresión combinada de diferentes antígenos en los blastos leucémicos y en los diferentes linajes linfoides y mieloides, en comparación con los fenotipos de células normales en distintos estadios de diferenciación es muy útil para clasificar inmunológicamente distintos tipos de leucemias y para el seguimiento terapéutico de estos pacientes, permitiendo discriminar las células neoplásicas de las células normales incluso cuando estas están presentes en frecuencias muy bajas $(9,10-13)$.

En la actualidad las casas comerciales disponen de una gran cantidad de anticuerpos que se emplean para el diagnóstico inmunofenotípico de neoplasias hematopoyéticas. Dentro de los parámetros de control de calidad en los 
laboratorios de citometría es indispensable optimizar cada reactivo antes de su uso evaluando la intensidad de fluorescencia de cada anticuerpo para asegurar que emiten la señal esperada, así como para excluir la aparición de interacciones no deseadas entre reactivos. Para llevar a cabo este proceso es recomendable utilizar una muestra de sangre periférica normal o MO normal que contenga poblaciones positivas y negativas para el anticuerpo de interés (11).

Dada la dificultad de tener patrones de referencia de médulas normales, el objetivo del presente trabajo consistió en describir una metodología adecuada para cuantificar en términos absolutos y relativos distintas subpoblaciones en MO normal y analizar la expresión de diferentes marcadores asociados a diferenciación. Esto con el fin de establecer diferentes rangos de expresión para cada marcador y los valores de referencia de las diferentes poblaciones celulares, lo cual podría aplicarse para otros laboratorios de citometría de flujo que realicen diagnóstico inmunofenotípico de neoplasias hematológicas.

\section{Materiales y métodos}

\section{Recolección de muestras de médula ósea (MO)}

Teniendo en cuenta la dificultad de obtener muestras de MO normal, en el presente estudio se procesaron en total 10 muestras de MO, de las cuales se seleccionaron 5 con viabilidad celular superior al $90 \%$ determinada mediante tinción con 7-Actinomicina D (7-AAD BDB). Estas muestras provenían de pacientes sometidos a reemplazo de cadera en el Servicio de Ortopedia del Hospital Universitario San Ignacio (2 hombres y 3 mujeres), quienes de forma voluntaria donaron la muestra después de firmar un formato de consentimiento informado aprobado por el comité de ética de la Pontificia Universidad Javeriana. Los pacientes fueron seleccionados de acuerdo a los siguientes criterios de inclusión: Individuos mayores de 60 años de edad (69 \pm 7 ; rango: 61-79 años), sin enfermedad hematológica de base y no sometidos a tratamiento con factores de crecimiento, o drogas quimioterapéuticascitotóxicas/inmunosupresoras. En el procedimiento, después de la exposición de la cavidad acetabular, con el uso del reamer, se recolectó la muestra de rimado y/o médula en un recipiente estéril. La muestra fue transferida a un tubo con EDTA (0,2 ml EDTA: $1 \mathrm{ml} \mathrm{MO})$ y transportada a temperatura ambiente y en oscuridad al laboratorio de hematología de la Facultad de Ciencias de la Pontificia Universidad Javeriana.

\section{Disgregación de las muestras de MO}

La muestra de rimado y/o médula recolectada (volúmen mínimo requerido: $5 \mathrm{ml}$ ), fue depositada en un mortero estéril, con PBS pH 7,2 + EDTA 2mM, para macerarla y deshacer el material óseo, y posteriormente filtrada con gasa estéril para eliminar exceso de grasa y espículas de hueso que pudieran interferir en el marcaje mediante CMF. Después de realizar este proceso se obtuvieron aproximadamente $3-5 \mathrm{~mL}$ de muestra total.

\section{Marcaje de antígenos de membrana y citoplasma mediante citometría de flujo}

Para realizar el análisis inmunofenotípico de las distintas subpoblaciones celulares en las muestras de MO disgregadas y filtradas, se empleó un panel de anticuerpos monoclonales y policlonales útiles para la caracterización fenotípica de leucemias agudas y SMD (8) combinados en 4 fluorescencias distintas (Fluorocromos: FITC/PE/PERCPCY5.5/APC), con un protocolo que combina marcaje celular de antígenos de membrana y de citoplasma (Tabla 1). En los tubos a los que se realizó exclusivamente el marcaje de antígenos de membrana (Tabla 2: tubos 4-9), a 100 ul de muestra de MO se le adicionó la cantidad adecuada de anticuerpo conjugado con fluorocromo (Tabla 2) y se incubó durante 15 minutos a temperatura ambiente y en oscuridad. Una vez transcurrido este tiempo, se adicionó $1 \mathrm{~mL}$ de solución de lisis (FACS lysing solution-BDB) durante 10 minutos y se realizaron dos lavados con $2 \mathrm{~mL}$ de PBS, seguidos de centrifugación por 5 minutos a $2000 \mathrm{rpm}$.

Para llevar a cabo el marcaje simultáneo de antígenos de membrana y citoplasma (Tabla 2: tubo 3), se empleó el kit de fijación y permeabilización (InstraStain-Dako). En primer lugar se realizó el marcaje de antígenos de membrana, seguido de incubación con 100 uL de solución fijadora (Reactivo A) y posteriormente se adicionó solución de permeabilización (Reactivo B) para la detección inmunológica de antígenos intracelulares permitiendo que la superficie celular continúe intacta en conjunto con el anticuerpo específico del antígeno de citoplasma. Las incubaciones en cada paso fueron realizadas durante 30 minutos a temperatura ambiente y en oscuridad, seguidas de lavados con PBS. Como control de auto-fluorescencia, se procesaron 2 tubos adicionales (Tabla 2: tubos 1-2), sometidos a los mismos tratamientos descritos para los tubos 3-9, a excepción que a estos no se les adicionó anticuerpo conjugado.

Una vez realizado el marcaje y comprobada la compensación y calibración del citómetro, a cada tubo se le 
Tabla 1. Anticuerpos monoclonales utilizados para el marcaje de subpoblaciones celulares en MO normal en combinaciones de 4 fluorescencias distintas

\begin{tabular}{|c|c|c|c|c|}
\hline CD & Fluorocromo & Clon & Casa comercial & Reactividad \\
\hline CD11b & PE & $\mathrm{M} 1 / 70$ & $\mathrm{BDB}$ & $\begin{array}{l}\text { Línea granulocítica: neutrófilo, eosinófilo, } \\
\text { basófilo), monocitos, células dendríticas } \\
\text { mieloides }\end{array}$ \\
\hline CD13 & APC & WM15 & $\mathrm{BDB}$ & $\begin{array}{l}\text { Linaje mieloide (Precursores mieloides, Línea } \\
\text { granulocítica: neutrófilo, eosinófilo, basófilo), } \\
\text { monocitos, células dendríticas mieloides }\end{array}$ \\
\hline CD14 & PE & M5E2 & $\mathrm{BDB}$ & Monocitos maduros \\
\hline CD15 & FITC & MMA & BDB & Línea granulocítica: neutrófilos y eosinófilos \\
\hline CD16 & PE & $\mathrm{GO} 22$ & $\mathrm{BDB}$ & $\begin{array}{l}\text { Receptor Fc gamma III expresado en granulocitos, } \\
\text { células NK y macrófagos. }\end{array}$ \\
\hline CD33 & PerCP & P67.6 & BDB & Linaje mieloide \\
\hline CD34 & APC & $8 \mathrm{G} 12$ & $\mathrm{BDB}$ & Células progenitoras hematopoyéticas \\
\hline CD34 & FITC & $8 \mathrm{G} 12$ & BDB & \\
\hline CD36 & $\mathrm{PE}$ & G155-228 & Pharmingen & $\begin{array}{l}\text { Línea eritroide, monocitos, células dendríticas, } \\
\text { plaquetas }\end{array}$ \\
\hline CD38 & APC & HB7 & $\mathrm{BDB}$ & \\
\hline CD45 & PercP & 2D1 & BDB & Antígeno común leucocitario \\
\hline CD45 & APC & $\mathrm{T} 29 / 33$ & DAKO & \\
\hline CD64 & FITC & MOPC21 & $\mathrm{BDB}$ & Línea granulocítica: neutrófilos y monocitos \\
\hline CD71 & FITC & L01.1 & $\mathrm{BDB}$ & $\begin{array}{l}\text { Precursores mieloides, Línea eritroide, } \\
\text { neutrófilos, monocitos }\end{array}$ \\
\hline CD117 & $\mathrm{PE}$ & 104D2 & $\mathrm{BDB}$ & Precursores mieloides, mastocitos, promielocitos \\
\hline CD123 & $\mathrm{PE}$ & 9F5 & $\mathrm{BDB}$ & $\begin{array}{l}\text { Precursores mieloides, basófilos, células } \\
\text { dendríticas, monocitos }\end{array}$ \\
\hline HLA-DR & FITC & L243(G46-6) & $\mathrm{BDB}$ & $\begin{array}{l}\text { Células progenitoras hematopoyéticas, } \\
\text { monocitos, células dendríticas, linfocitos B }\end{array}$ \\
\hline MPO & $\mathrm{PE}$ & HM47 & Dako & $\begin{array}{l}\text { Linaje mieloide (Línea granulocito-neutrófilo, } \\
\text { monocitos) }\end{array}$ \\
\hline TdT & FITC & IS001 & Dako & Precursores linfoides \\
\hline
\end{tabular}

CD: cluster diferentiation, FITC, isotiocianato de fluoresceína, PE, ficoeritrina, PerCP, peridinina clorofila proteína, APC, aloficocianina, BDB: Becton Dickinson Bioscience. 
Tabla 2. Panel Inmunofenotípico utilizando 4 fluorescencias distintas y esferas fluorescentes.

\begin{tabular}{llllll}
\hline Fluorocromo & FITC & PE & PERCP & APC & Esferas \\
\hline Cantidad por tubo & $5 \mathrm{uL}$ & $5 \mathrm{uL}$ & $5 \mathrm{uL}$ & $3 \mathrm{uL}$ & $10 \mathrm{uL}$ \\
Tubo 1 & supBLANCO & supBLANCO & supBLANCO & supBLANCO & + \\
Tubo 2 & citBLANCO & citBLANCO & citBLANCO & citBLANCO & + \\
Tubo 3 & nTdT & cyMPO & CD45 & CD34 & + \\
Tubo 4 & CD34 & CD11b & CD45 & CD34 & + \\
Tubo 5 & HLA-DR & CD117 & CD45 & CD34 & + \\
Tubo 6 & CD64 & CD14 & CD45 & CD38 & + \\
Tubo 7 & CD71 & CD36 & CD45 & CD34 & + \\
Tubo 8 & CD15 & CD16 & CD33 & CD45 & + \\
Tubo 9 & HLA-DR & CD123 & CD45 & CD34 & + \\
\hline
\end{tabular}

Sup: superficie, Cit: citoplasma, FITC, isotiocianato de fluoresceína, PE, ficoeritrina, PerCP, peridinina clorofila proteína, APC, aloficocianina, n: antígeno nuclear, cy: antígeno citoplasmático.

adicionó $10 \mathrm{uL}$ de esferas fluorescentes (Cytocount-Dako) y las muestras se adquirieron en el citómetro de flujo FACSCalibur BDB. Se adquirieron 100,000 eventos totales y se realizó un "gate" de 1,000,000 de eventos CD34+ y en el caso de mastocitos CD117++ debido a su baja frecuencia.

Para llevar a cabo la compensación del equipo se empleó una muestra de sangre periférica normal marcada con las siguientes combinaciones de anticuerpos monoclonales en cuatro fluorescencias distintas: CD3FITC/CD4PE/ CD3PERCP/CD8APC. Posteriormente, se ajustaron las señales de fluorescencia y voltajes de cada detector (FL-1/ FL-2, FL-3 y FL-4) con el fin de asegurar la discriminación adecuada entre las señales positivas y negativas. La calibración del equipo se realizó empleando microesferas fluorescentes (Calibrite BDB) siguiendo las recomendaciones del fabricante.

\section{Análisis de resultados}

El análisis de los datos se llevó a cabo con el programa informático Paint-A-Gate BDB, seleccionando las células de interés por su expresión de marcadores específicos de línea y su granularidad, así como una selección dual por medio de CD45 versus granularidad (SSC) (Figura 1). En este análisis se evaluaron las siguientes variables: frecuencia de las distintas subpoblaciones celulares en términos absolutos y relativos y la expresión de los diferentes antígenos en las distintas subpoblaciones en términos de intensidad media de fluorescencia (MFI).

Para calcular el número absoluto de cada subpoblación celular en cada tubo realizado, se aplicó la siguiente fórmula (11):

$$
\begin{aligned}
& {\left[\frac{\# \text { célulasengate }}{\# \text { microesferasengate }} \times \frac{\# \text { microesferasañadidasportubo }(a)}{\text { volumendemuestra }(u L)(b)}\right.} \\
& \times \text { factordeconversión }(c)=\text { células } / u L]
\end{aligned}
$$

Donde: $a$ es el número total de microesferas añadidas al tubo que se calcula de la siguiente forma: volúmen de microesferas añadidas al tubo (ej. $20 \mathrm{ul}$ ) x concentración de microesferas (microesferas/ul) (este dato lo provee el fabricante), $b$ es el volúmen total de la muestra de $\mathrm{MO}$ en el momento de su obtención y $c$ corresponde al factor de corrección que será igual al volumen de la muestra una vez disgregada y concentrada (ej., $5000 \mathrm{ul}$ ) dividido por el volumen de la muestra concentrada utilizada para el marcaje en cada tubo (ej. 100ul). Así, en el protocolo descrito el factor de corrección será: 5000ul/100ul= 50 .

Para el análisis estadístico de los datos, se realizó un análisis descriptivo, determinando para las variables cuantitativas: media, mediana, desviación estándar y para las variables cualitativas las frecuencias absolutas y relativas, empleando el paquete estadístico SPSS versión 15 y se aplicó el test de Mann Whitney. Se consideraron como diferencias significativas cuando $\mathrm{p}<0,005$. 

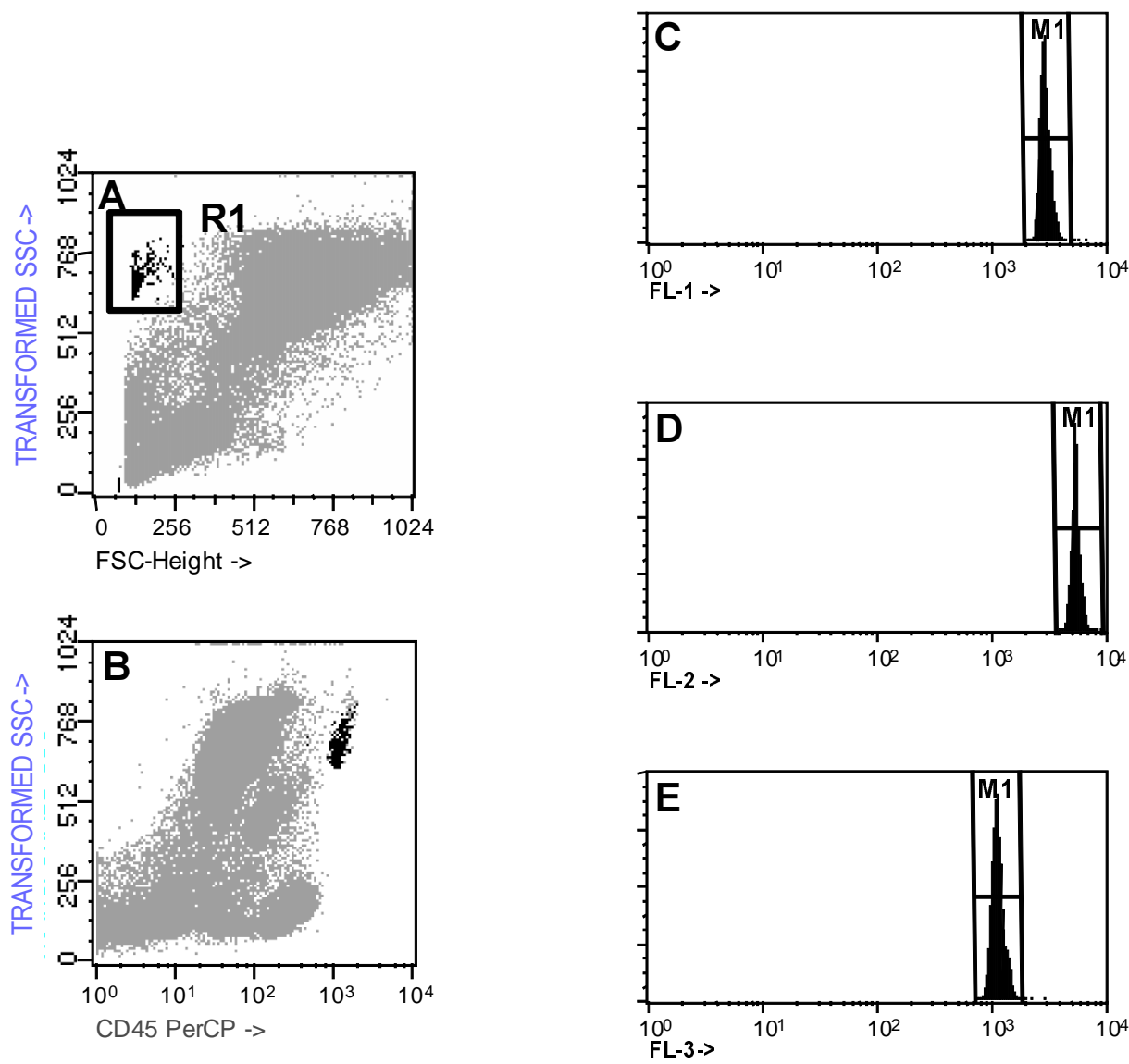

Figura 1. Ejemplo de análisis de esferas en una muestra de MO (eventos de color negro en los paneles A y B) para estimar un recuento absoluto por unidad de volumen de MO. En el panel A se representa la complejidad (side scatter-SSC-) y y el tamaño (forward scatter-FSC-). El análisis se inicia realizando una selección de las esferas en FSC vs SSC (Región 1: panel A). El panel B muestra la región de esferas (R1) en relación con la expresión de CD45 de las diferentes subpoblaciones celulares de MO. Los paneles C-E muestran la intensidad de fluorescencia de las esferas para los canales FL-1 (FITC), FL2 (PE) y FL-3 (PercP).

\section{Resultados}

\section{Distribución de las diferentes subpoblaciones celulares de MO normal}

En la tabla 3 se muestran los valores absolutos y relativos de las poblaciones leucocitarias de MO normal de 5 individuos diferentes.

\section{Características de dispersión de luz e inmunofenotipo de las diferentes subpoblaciones celulares de MO normal}

En las tablas 4-10 se muestran los valores promedio, desviación estándar y rangos para las características de dispersión de la luz e intensidad de fluorescencia de marcadores de linaje linfoide y mieloide en las distintas poblaciones leucocitarias de MO normal de 5 individuos diferentes.

Al investigar las posibles diferencias existentes entre los marcadores inmunofenotípicos expresados en las células precursoras CD34+ de origen linfoide y mieloide, observamos que a pesar de no encontrar diferencias estadísticamente significativas, las células CD34+ de origen mieloide se caracterizan por una expresión más elevada de CD34, CD45, y HLA-DR en conjunto con valores superiores de tamaño y granularidad (Tabla 4; Figura 2).

En relación a la línea granulocítica, observamos tal como está reportado en la literatura (4) que los neutrófilos se 
Tabla 3. Valores normales (relativos y absolutos) de subpoblaciones celulares de MO.

\begin{tabular}{lllll}
\hline Subpoblación celular & \multicolumn{2}{c}{ Porcentaje de la celularidad Total } & \multicolumn{2}{c}{ Número absoluto (células/uL) } \\
& Media \pm DS & Rango & Media \pm DS & Rango \\
\hline Células CD34 totales & $1,5 \pm 0,7$ & $0,7-2,5$ & $117 \pm 92$ & $14-245$ \\
CD34+ linfoides & $0,2 \pm 0,2$ & $0,1-0,6$ & $12 \pm 14$ & $2-37$ \\
CD34+ mieloides & $1,4 \pm 0,5$ & $0,6-1,9$ & $102 \pm 91$ & $12-235$ \\
Linea granulocítica total & $56 \pm 9$ & $42-64$ & $3486 \pm 3138$ & $685-8151$ \\
Promielocitos & $1,3 \pm 1,1$ & $0,7-2,1$ & $108 \pm 77$ & $5-204$ \\
Mielocitos & $9 \pm 2$ & $6-11.6$ & $800 \pm 622$ & $92-1538$ \\
Metamielocitos & $22 \pm 11$ & $14-42$ & $1589 \pm 1102$ & $227-2895$ \\
Neutrófilos & $30 \pm 9$ & $22-46$ & $2272 \pm 1533$ & $311-4201$ \\
Eosinófilos & $3,6 \pm 1$ & $2-5$ & $150 \pm 109$ & $2-309$ \\
Basófilos & $0,2 \pm 0,2$ & $0,1-0,7$ & $13 \pm 7$ & $5-22$ \\
Mastocitos & $0,01 \pm 0,006$ & $0,01-0,02$ & $8,5 \pm 11$ & $1-28$ \\
Promonocitos & $0,7 \pm 0,2$ & $0,5-0,1$ & $49 \pm 27$ & $2-72$ \\
Monocitos & $4 \pm 1$ & $3-5$ & $323-225$ & $40-603$ \\
Células dendríticas derivadas & $0,3 \pm 0,007$ & $0,3-0,4$ & $3 \pm 1,7$ & $2-5$ \\
de monocito & & & $37 \pm 23$ & $3-70$ \\
Células dendríticas & $0,3 \pm 0,08$ & $0,2-0,4$ & $1286 \pm 706$ & $146-1870$ \\
plasmocitoides & & &
\end{tabular}

Resultados expresados como media \pm 1 desviación estándar (DS).

Tabla 4. Precursores CD34+: análisis de intensidad media de fluorescencia de complejidad interna y marcadores de linaje linfoide y mieloide.

\begin{tabular}{|c|c|c|c|c|c|}
\hline \multirow[t]{2}{*}{ Parámetro } & \multicolumn{2}{|c|}{ Precursores linfoides CD34+ } & \multicolumn{2}{|c|}{ Precursores mieloides CD34+ } & \multirow[t]{2}{*}{ Valor de $\mathbf{P}$} \\
\hline & Media \pm DS & Rango & Media \pm DS & Rango & \\
\hline FSC & $418 \pm 196$ & $206-630$ & $608 \pm 136$ & $378-316$ & NS \\
\hline SSC & $201 \pm 88$ & $125-300$ & $324 \pm 329$ & $282-373$ & \\
\hline CD45 & $17 \pm 3$ & $13-21$ & $33 \pm 15$ & $15-53$ & \\
\hline CD34 & $165 \pm 139$ & $30-325$ & $278 \pm 92$ & $147-375$ & \\
\hline HLA-DR & $203 \pm 21$ & $188-218$ & $572 \pm 155$ & $396-729$ & \\
\hline TdT & $185 \pm 81$ & $96-290$ & $\mathrm{NE}$ & $\mathrm{NE}$ & \\
\hline MPO & $\mathrm{NE}$ & $\mathrm{NE}$ & $306 \pm 318$ & $22-256$ & \\
\hline CD117 & $\mathrm{NE}$ & $\mathrm{NE}$ & $153 \pm 56$ & $111-218$ & \\
\hline CD123 & $\mathrm{NE}$ & $\mathrm{NE}$ & $35 \pm 12$ & $27-50$ & \\
\hline CD13 & $\mathrm{NE}$ & $\mathrm{NE}$ & $16 \pm 3$ & $12-19$ & \\
\hline
\end{tabular}

Resultados expresados como media \pm 1 desviación estándar (DS), NE: marcador fenotípico no expresado en esta línea, NS: no estadísticamente significativo (p>0,05), FSC: Forward scatter, SSC: side scatter. 
caracterizan por presentar una expresión significativamente más elevada de CD45 y CD11b respecto a los promielocitos, mielocitos y metamielocitos y son más complejos (granularidad-SSC-) respecto a los metamielocitos. Por otra parte, los promielocitos muestran niveles elevados de CD13 y corresponden a la única subpoblación celular dentro de este linaje con expresión de CD117 (tabla 5; figura 3). Además la línea granulocítica mostró expresión para los marcadores CD15, CD16, MPO, CD33 y CD71, marcadores expresados principalmente desde el estadio madurativo de promielocito (Tabla 6) (2).

En la línea monocítica se encontraron diferencias estadísticamente significativas en la expresión de los marcadores CD45, CD13, CD11b, y CD14 en los monocitos respecto a promonocitos (Tabla 7; Figura 4). Por otra parte en la tabla 8 se presentan los niveles de expresión de CD45, CD15, CD33 y CD16 en las células dendríticas derivadas del monocito. Estas células muestran niveles superiores de expresión del antígeno CD45 respecto a la observada en monocitos $(\mathrm{p}=0,008)$.

Por otra parte, el análisis de los precursores eritroides mostró pérdida de expresión del marcador CD45, con expresión de CD36 (Tabla 9). Además se identifican dos subgrupos fenotípicos en relación a la expresión de CD71, una proporción (aproximadamente el $40 \%$ de los precursores eritroides) son CD71+ (corresponden fenotípicamente según la literatura a proeritroblastos) (2) y el $60 \%$ restante son CD71+ débil correspondiendo a eritroblastos (2) (Tabla 9; Figura 5).

En la tabla 10 se presenta el análisis de intensidad media de fluorescencia de los marcadores HLA-DR, CD45 y CD123 en las células dendríticas plasmacitoides, en las que se observan niveles elevados de expresión de HLA-DR y CD123 característicos de estas células (Figura 6), (6).

El análisis de intensidad media de fluorescencia de marcadores fenotípicos expresados en basófilos es presentado en la tabla 11. Estas células se caracterizan por la co-expresión de los marcadores CD45+, CD13+, CD11b+ y CD123+ (Figura 6).

El análisis de la complejidad interna y la expresión de los marcadores CD45 y CD117 en mastocitos son presentados en la tabla 12. Estas células muestran alta intensidad de CD117 con expresión de CD45 y negatividad para CD34 (Figura 7).

Tabla 5. Línea granulocito-neutrófilo: análisis de intensidad media de fluorescencia de complejidad interna y marcadores de linaje mieloide.

\begin{tabular}{|c|c|c|c|c|c|c|c|c|c|c|c|}
\hline \multirow[t]{2}{*}{ Parámetro } & \multicolumn{2}{|c|}{$\begin{array}{c}\text { Línea } \\
\text { granulocítica total }\end{array}$} & \multicolumn{2}{|c|}{ Promielocito } & \multicolumn{2}{|c|}{ Mielocito } & \multicolumn{2}{|c|}{ Metamielocito } & \multicolumn{2}{|c|}{ Neutrófilo } & \multirow[t]{2}{*}{ Valor deP } \\
\hline & Media \pm DS & Rango & Media \pm DS & Rango & Media \pm DS & Rango & Media $\pm \mathrm{DS}$ & Rango & Media \pm DS & Rango & \\
\hline FSC & $671 \pm 66$ & $614-780$ & $723 \pm 73$ & $645-826$ & $800 \pm 622$ & $92-1538$ & $659 \pm 71$ & $600-764$ & $642 \pm 69$ & $574-754$ & NS \\
\hline SSC & $699 \pm 18$ & $671-717$ & $551 \pm 279$ & $65-744$ & $693 \pm 64$ & $595-752$ & $599 \pm 221$ & $203-711$ & $715 \pm 4$ & $712-722$ & $\begin{array}{c}0,008 \\
+\end{array}$ \\
\hline CD45 & $43 \pm 15$ & $30-70$ & $33 \pm 34$ & $23-42$ & $35 \pm 10$ & $22-50$ & $34 \pm 9$ & $27-50$ & $57 \pm 19$ & $39-88$ & $\begin{array}{c}<0,05 \\
*\end{array}$ \\
\hline CD13 & $18 \pm 8$ & $10-32$ & $59 \pm 17$ & $35-78$ & $8,6 \pm 2$ & $6-12$ & $5 \pm 0,9$ & 46 & $26 \pm 17$ & $15-58$ & $\begin{array}{c}<0,05 \\
* *\end{array}$ \\
\hline CD11b & $1249 \pm 537$ & $554-1957$ & $28 \pm 8$ & $15-40$ & $32,4 \pm 9,3$ & $17-41$ & $592 \pm 715$ & $8-1432$ & $2094 \pm 712$ & 999-2858 & $\begin{array}{c}0,008 \\
* * *\end{array}$ \\
\hline CD117 & $\mathrm{NE}$ & $\mathrm{NE}$ & $137 \pm 316$ & $111-163$ & $\mathrm{NE}$ & $\mathrm{NE}$ & $\mathrm{NE}$ & $\mathrm{NE}$ & $\mathrm{NE}$ & $\mathrm{NE}$ & $\mathrm{NA}$ \\
\hline
\end{tabular}

Resultados expresados como media \pm 1 desviación estándar (DS), NE: marcador fenotípico no expresado en este estadio madurativo, NS: no estadísticamente significativo ( $\mathrm{p}>0,05)$, FSC: Forward scatter, SSC: side scatter, +p<0,05 al comparar metamielocitos vs neutrófilos, $* \mathrm{p}<0,05$ al comparar neutrófilos vs los demás estadios madurativos, $* * * \mathrm{p}<0,05$ al comparar promielocitos vs los demás estadios madurativos, ***p<0,05 al comparar neutrófilos vs vs los demás estadios madurativos. 
Tabla 6. Línea granulocito-neutrófilo: análisis de intensidad media de fluorescencia de otros marcadores de linaje mieloide.

\begin{tabular}{lll}
\hline Parámetro & $\begin{array}{l}\text { Línea granulocítica total } \\
\text { Media } \pm \text { DS }\end{array}$ & Rango \\
\hline CD15 & $1401 \pm 369$ & $873-1734$ \\
CD33 & $23 \pm 2$ & $22-25$ \\
CD16 & $213 \pm 261$ & $28-398$ \\
MPO & $1424 \pm 1105$ & $330-2527$ \\
CD64 & $44 \pm 12$ & $29-57$ \\
CD71 & $255 \pm 196$ & $43-481$ \\
\hline
\end{tabular}

Resultados expresados como media \pm 1 desviación estándar (DS).

Tabla 7: Linaje Monocítico: análisis de intensidad media de fluorescencia y marcadores de linaje monocítico

\begin{tabular}{cccccc}
\hline & \multicolumn{2}{c}{ Promonocito } & \multicolumn{2}{c}{ Monocito } & Valor de P \\
\hline Parámetro & Media \pm DS & Rango & Media \pm DS & Rango & NS \\
FSC & $581 \pm 107$ & $434-734$ & $564 \pm 225$ & $390-562$ & NS \\
SSC & $528 \pm 82$ & $398-609$ & $470 \pm 92$ & $327-562$ & NA \\
HLA-DR & NE & NE & $557 \pm 427$ & $138-1248$ & 0,008 \\
CD45 & $46 \pm 27$ & $18-82$ & $131 \pm 40$ & $87-180$ & 0,008 \\
CD14 & $12 \pm 4$ & $9-19$ & $1532 \pm 856$ & $1021-1050$ & NS \\
CD64 & $118- \pm 34$ & $92-178$ & $112 \pm 32$ & $88-168$ & 0,029 \\
CD11b & $32 \pm 17$ & $9-49$ & $1234 \pm 776$ & $119-1819$ & 0,029 \\
CD13 & $14 \pm 4$ & $8-18$ & $31- \pm 9$ & $20-41$ & NA \\
CD15 & $\mathrm{NE}$ & $\mathrm{NE}$ & $63 \pm 43$ & $27-122$ & NA \\
MPO & $\mathrm{NE}$ & $\mathrm{NE}$ & $338 \pm-282$ & $42-406$ & NA \\
CD33 & $\mathrm{NE}$ & $\mathrm{NE}$ & $54 \pm-8$ & $45-65$ & NA \\
CD123 & $\mathrm{NE}$ & $\mathrm{NE}$ & $58 \pm 40$ & $27-126$ & NA \\
CD16 & $\mathrm{NE}$ & $\mathrm{NE}$ & $42 \pm 24$ & $16-73$ & \\
\hline
\end{tabular}

Resultados expresados como media \pm 1 desviación estándar (DS), NA: no analizado, NE: marcador fenotípico no evaluado en cada subpoblación debido a su expresión simultánea en los dos estadios madurativos, NS: no estadísticamente significativo (p>0,05), FSC: Forward scatter; SSC: side scatter. 
Tabla 8: Células dendríticas derivadas de monocito: análisis de intensidad media de fluorescencia de marcadores mieloides

\begin{tabular}{ccc}
\hline Parámetro & \multicolumn{2}{c}{ Célula dendrítica derivada del Monocito } \\
\hline & Media \pm DS & Rango \\
\hline FSC & $766 \pm 163$ & $581-890$ \\
SSC & $493 \pm 32$ & $465-513$ \\
CD45 & $514 \pm 206$ & $369-751$ \\
CD15 & $129 \pm 23$ & $113-146$ \\
CD33 & $35 \pm 16$ & $24-47$ \\
CD16 & $226 \pm 39$ & $189-254$ \\
\hline
\end{tabular}

Resultados expresados como media \pm 1 desviación estándar (DS), FSC: Forward scatter; SSC: side scatter.

Tabla 9. Línea eritroide: análisis de intensidad media de fluorescencia de marcadores asociados a este linaje.

\begin{tabular}{ccc}
\hline & \multicolumn{2}{c}{ Línea Eritroide } \\
\hline Parámetro & Media \pm DS & Rango \\
\hline FSC & $224 \pm 75$ & $180-357$ \\
SSC & $162 \pm 36$ & $120-200$ \\
CD45 & $4 \pm 3$ & $2-10$ \\
CD71+ & $1249 \pm 1388$ & $681-1640$ \\
CD71 débil & $22 \pm 7$ & $12-128$ \\
CD36 & $78 \pm 59$ & $30-173$ \\
\hline
\end{tabular}

Resultados expresados como media \pm 1 desviación estándar (DS).

Tabla 10. Análisis de intensidad media de fluorescencia de marcadores fenotípicos en células dendríticas plasmacitoides.

\begin{tabular}{ccc}
\hline & \multicolumn{2}{c}{ Células dendríticas plasmacitoides } \\
\hline Parámetro & Media \pm DS & Rango \\
\hline FSC & $420 \pm 110$ & $350-615$ \\
SSC & $292 \pm 38$ & $248-331$ \\
HLA-DR & $827 \pm 291$ & $530-1273$ \\
CD45 & $68 \pm 36$ & $29-110$ \\
CD123 & $1463 \pm 293$ & $1123-1911$ \\
\hline
\end{tabular}

Resultados expresados como media \pm 1 desviación estándar (DS) 

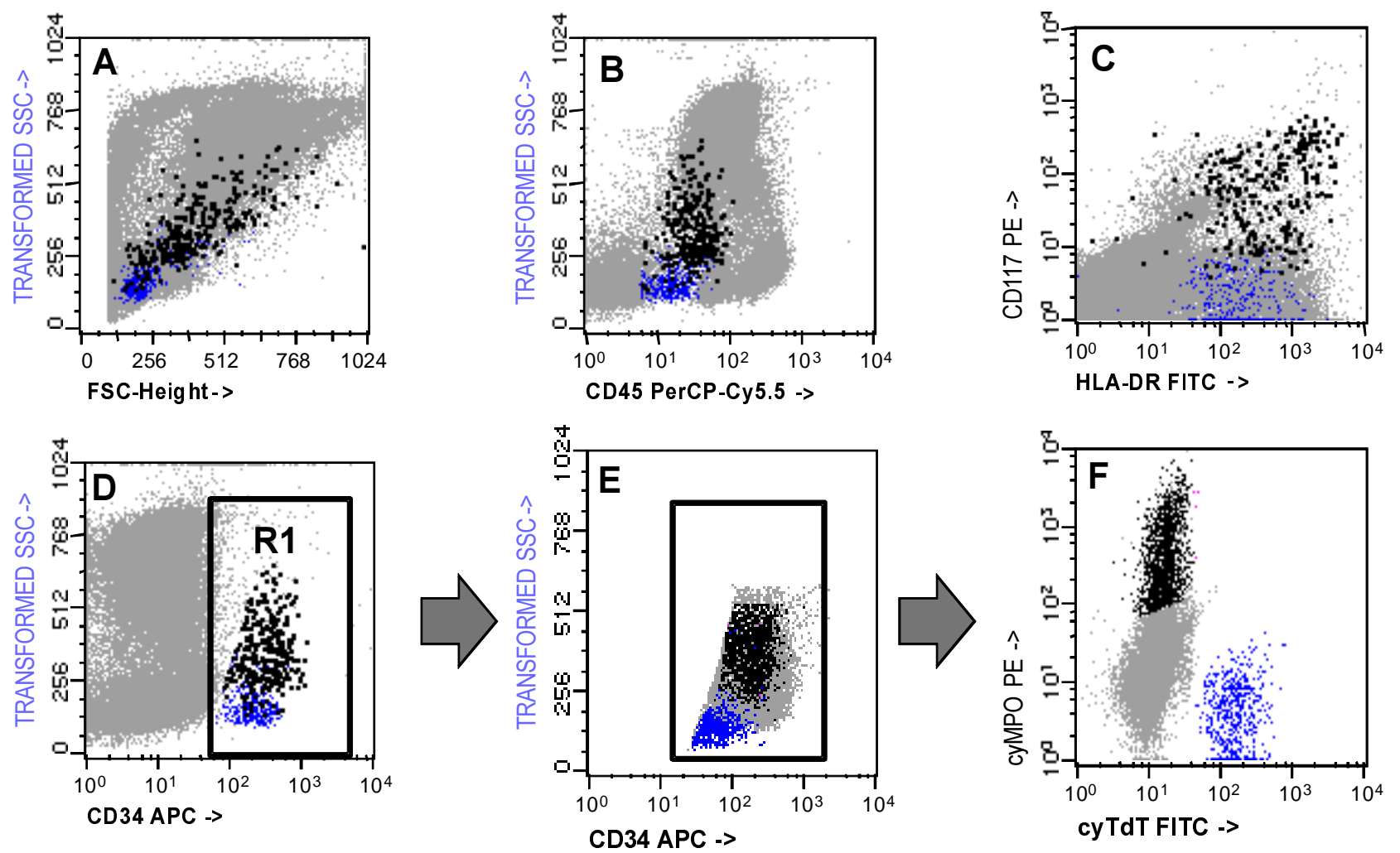

Figura 2. Análisis fenotípico de precursores hematopoyéticos CD34+ utilizando un marcaje con cuatro fluorescencias. Panel A: Análisis de la complejidad (side scatter-SSC-) y el tamaño (forward scatter -FSC-). Panel B: Expresión de CD45. Panel C: Expresión de HLA-DR y CD117. Paneles D y E: Selección de los eventos CD34+ y posterior análisis de la expresión de MPO y TdT (Panel F). Precursores linfoides (eventos de color azul): bajo FSC/SSC, CD45+ débil, CD117, HLA-DR+, CD34+, TdT+, MPO-. Precursores mieloides (eventos de color negro): FSC/SSC intermedio, CD45+ débil, CD117+, HLA-DR+, CD34+, TdT-, MPO+.
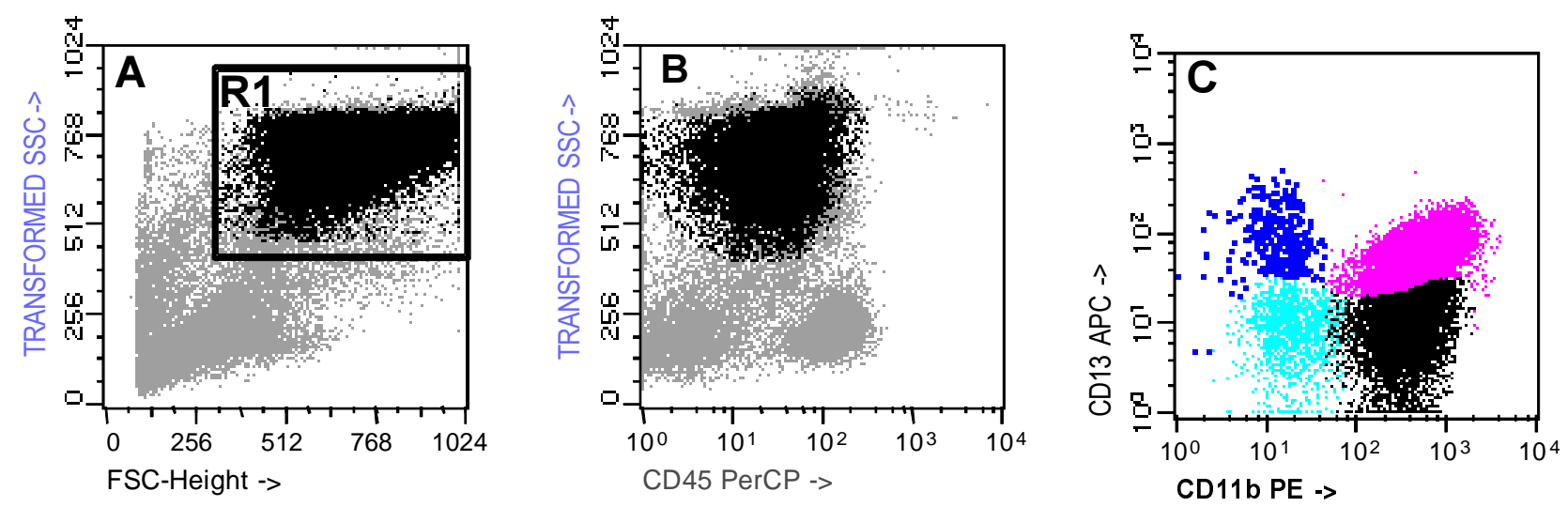

Figura 3. Análisis fenotípico de la línea granulocítica. Selección de la línea granulocítica por la complejidad (side scatter -SSC-) y el tamaño (forward scatter-FSC-) (Región R1, panel A). Posteriormente se realiza una segunda selección según la intensidad de fluorescencia para el marcador CD45 (Panel B). Las distintas subpoblaciones celulares se diferencian por su expresión de CD13 y CD11b: población de promielocitos CD13++/CD11b- (eventos azul oscuro), población de mielocitos CD13-/+/CD11b- (eventos azul claro), población de metamielocitos CD13-/CD11b+ (eventos de color negro) y población de neutrófilos CD13++/CD11b++ (eventos violeta). 

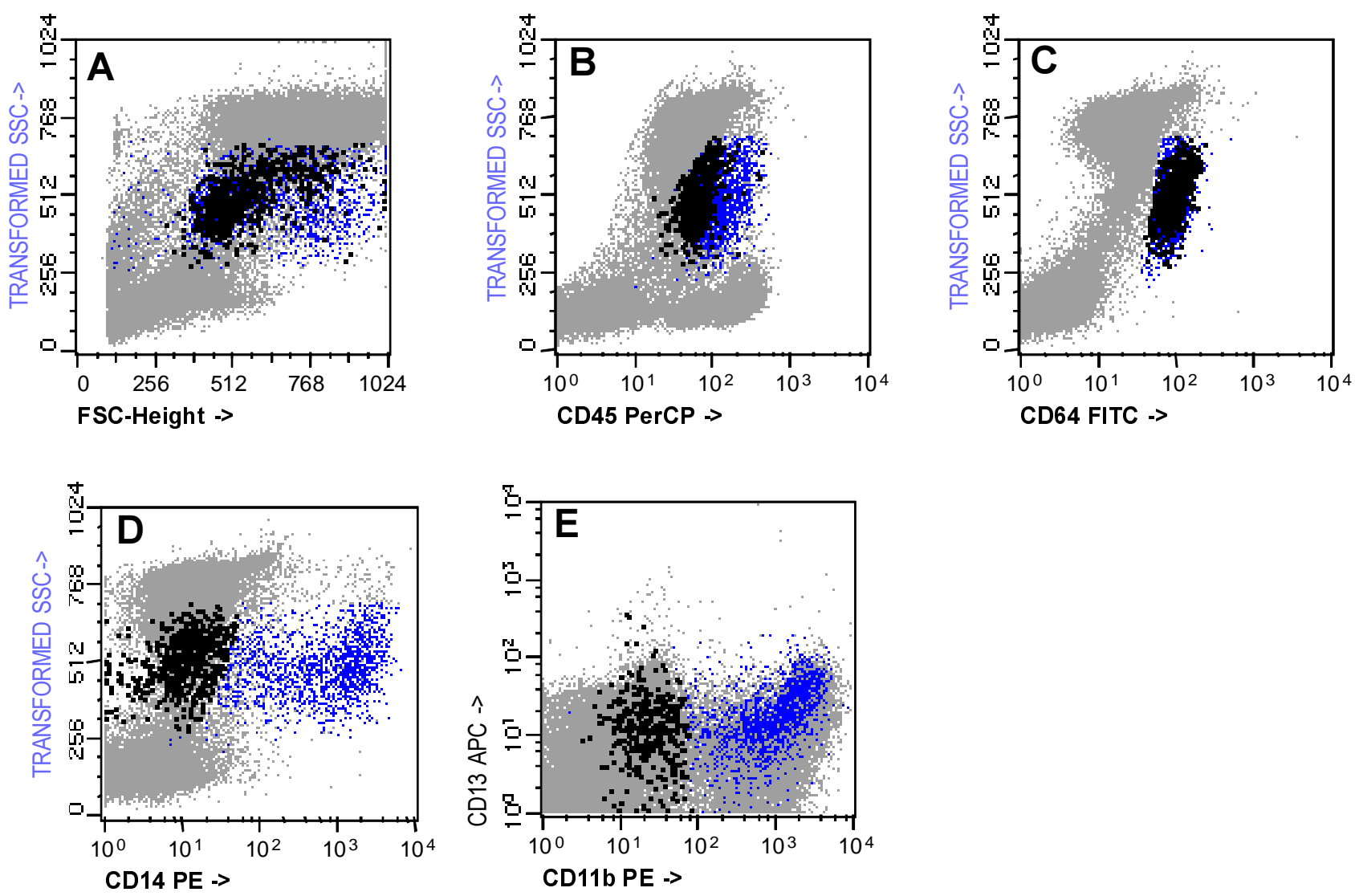

Figura 4. Análisis de la línea monocítica según la complejidad (side scatter-SSC-) y el tamaño (forward scatter-FSC-) (panel A). inmunofenotipo de promonocitos CD45+ débil, CD64++, CD14-, CD13+, CD11b+ débil) (eventos de color negro) y monocitos (CD45+, CD64++, CD14+, CD13+, CD11b+) (eventos de color azúl) (paneles B-E).
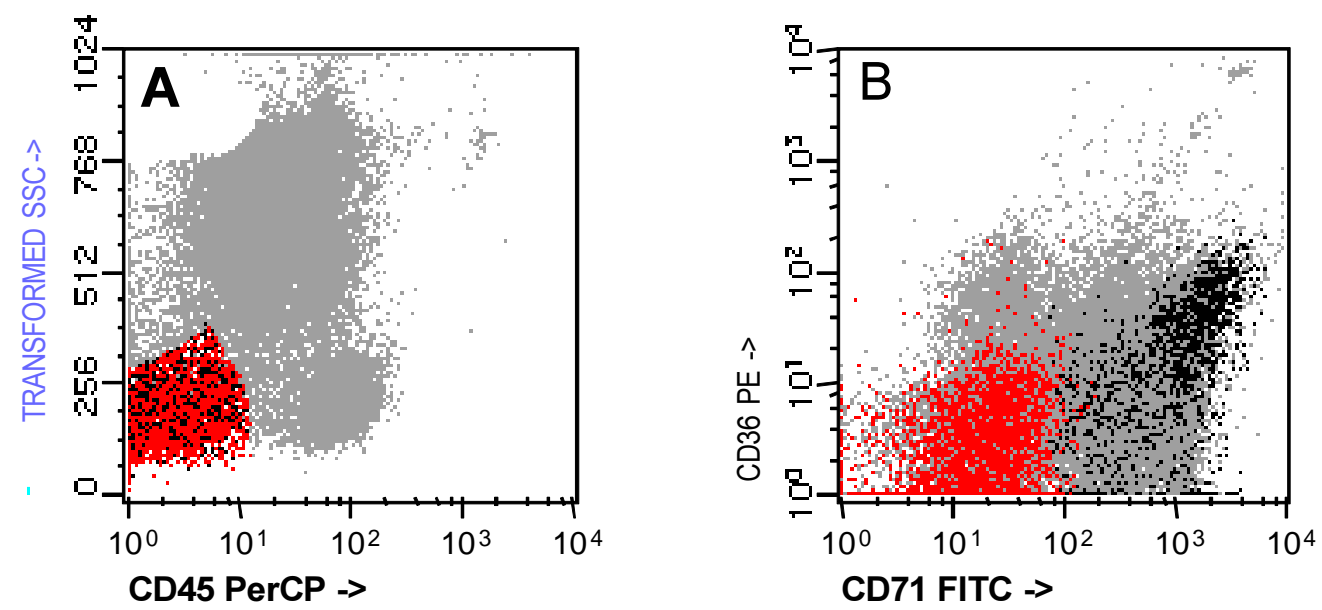

Figura 5. Análisis inmunofenotípico de la serie eritroide. Proeritroblastos CD45-, CD71-/+, CD36+ (eventos de color rojo, paneles A-B) y eritroblastos CD45-, CD71+, CD36+ (eventos de color negro, paneles A-B). 

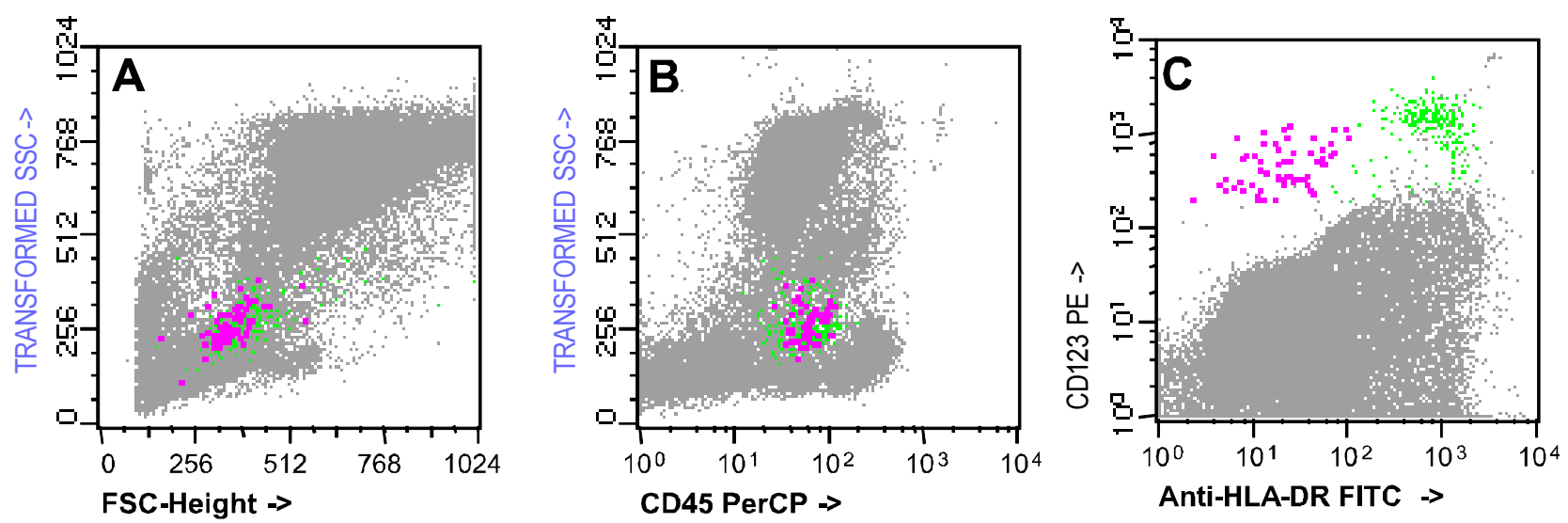

Figura 6. Análisis inmunofenotípico de basófilos (eventos de color violeta, paneles A-C): FSC/SSC bajo, CD45+, HLADR-, CD123+ y de células dendríticas plasmacitoides (eventos de color verde, paneles A-C): FSC/SSC bajo, CD45+, HLA$\mathrm{DR}+, \mathrm{CD} 123++$.

Tabla 11. Análisis de intensidad media de fluorescencia de marcadores fenotípicos en basófilos.

\begin{tabular}{ccc}
\hline Parámetro & \multicolumn{2}{c}{ Basófilos } \\
\hline & Media \pm DS & Rango \\
\hline FSC & $345 \pm 57$ & $281-431$ \\
SSC & $278 \pm 321$ & $246-331$ \\
CD45 & $184 \pm 257$ & $48-643$ \\
CD123 & $616 \pm 244$ & $404-1036$ \\
CD11b & $438 \pm 73$ & $386-490$ \\
CD13 & $41 \pm 34$ & $17-65$ \\
\hline
\end{tabular}

Resultados expresados como media \pm 1 desviación estándar (DS).

Tabla 12. Análisis de intensidad media de fluorescencia de marcadores fenotípicos en mastocitos.

\begin{tabular}{ccc}
\hline Parámetro & \multicolumn{2}{c}{ Mastocitos } \\
\hline & Media \pm DS & Rango \\
\hline FSC & $660 \pm 111$ & $481-752$ \\
SSC & $641 \pm 55$ & $581-728$ \\
CD45 & $347 \pm 589$ & $47-1400$ \\
CD117 & $3989 \pm 863$ & $3379-4600$ \\
\hline
\end{tabular}

Resultados expresados como media \pm 1 desviación estándar (DS). 

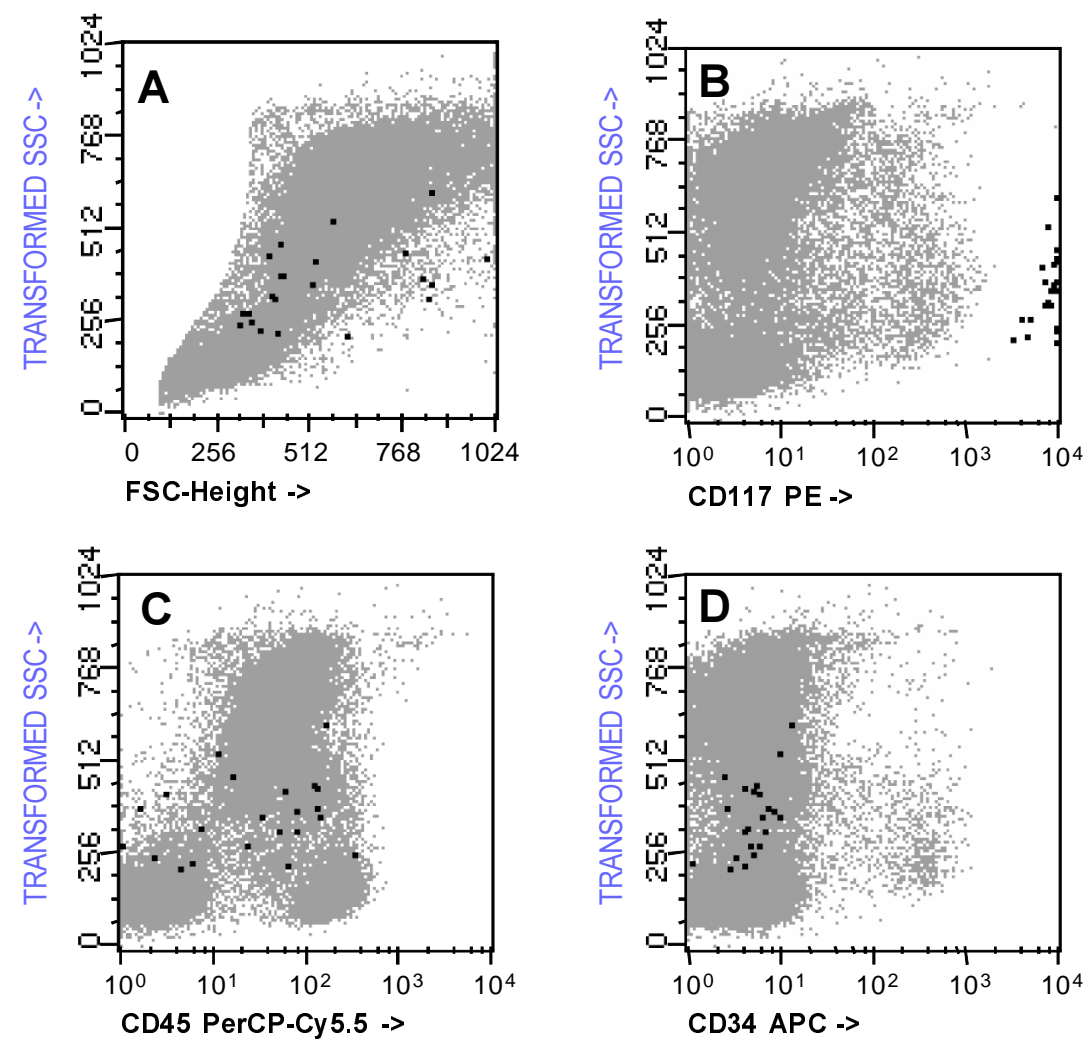

Figura 7. Análisis inmunofenotípico de mastocitos (eventos de color negro): FSC/SSC intermedio (panel A), CD117+++ (panel B), expresión heterogénea de CD45 (panel C) y negatividad para CD34 (panel D).

\section{Discusión}

Las leucemias agudas (LA) y los SMD son hemopatías malignas de características clínicas, biológicas y evolutivas muy heterogéneas $(1,2)$. Desde el punto de vista clínico-biológico, se ha avanzado notablemente en la identificación y caracterización molecular de estas enfermedades (3). En la actualidad, los criterios empleados para la clasificación diagnóstica de los pacientes con LA y SMD se fundamentan entre otras estrategias diagnósticas en el análisis inmunofenotípico de las distintas subpoblaciones celulares presentes en el tejido afectado (principalmente $\mathrm{MO}$ ), estableciendo la línea celular, su estadio madurativo y las aberraciones fenotípicas presentes en las células neoplásicas $(4-6,8,14)$. Por otra parte, el análisis inmunofenotípico de células normales de MO mediante CMF multiparamétrica es una herramienta de gran utilidad para la identificación de los fenotipos aberrantes en células hematopoyéticas malignas con implicación directa en el pronóstico, tratamiento y seguimiento de la enfermedad $(3,7,14-15)$.
En cuanto el manejo de muestras en CMF, se ha descrito gran variabilidad en los resultados en relación con el tipo de anticoagulante empleado en el momento de obtención de la muestra (heparina vs EDTA), con las condiciones de transporte y almacenamiento de las mismas, y en la fase analítica con el proceso de fijación y lisis de las muestras, variables que en conjunto tienen un impacto directo en la interpretación de los resultados (14). Por esta razón es fundamental establecer los valores de referencia en muestras normales para los distintos marcadores empleados en los paneles inmunofenotípicos de cada laboratorio de citometría para reducir la variabilidad a la hora de interpretar el fenotipo de células anormales en LMA y SMD.

En el presente trabajo se describe el procesamiento técnico de las muestras de MO, marcaje en cuatro fluorescencias distintas que puede ser aplicado a un mayor número de combinaciones de anticuerpos en distintas fluorescencias (> cuatro), lectura (adquisición en el citómetro de flujo), análisis de datos y los valores absolutos y relativos de las diferentes subpoblaciones por medio de la adición de 
esferas para la realización de estos recuentos, en conjunto con los valores promedio y rangos de intensidad media de fluorescencia para cada uno de los marcadores fenotípicos evaluados. Los diferentes paneles de anticuerpos conjugados con diversos fluorocromos y las técnicas de marcaje de antígenos localizados a nivel de la membrana celular como de citoplasma empleadas en el análisis, han sido previamente seleccionados, titulados y estandarizados en la unidad de citometría.

En relación con lo descrito en la literatura, diferentes estudios han establecido la secuencia de expresión de un gran número de antígenos a lo largo de los distintos estadios madurativos de las células de linaje mieloide y linfoide (3). Así, se ha establecido que en MO los precursores hematopoyéticos CD34+ muestran estadios madurativos bien definidos como son los precursores linfoides y los precursores mieloides (6). Los precursores linfoides B CD34+/CD19+ muestran además positividad nuclear para la enzima deoxinucleotidil transferasa terminal (TdT), expresión débil de CD45 y CD22, expresión citoplasmática (cy) de CD79a y reactividad fuerte para CD10 y HLA-DR entre otros marcadores $(3,4,16,17)$. Por otra parte, los precursores que darán origen al linaje mieloide muestran expresión débil de CD45 pero en conjunto con los marcadores CD117, CD123, HLA-DR, CD38, CD71 y CD13 con expresión parcial de CD15 y de mieloperoxidasa (MPO) a nivel citoplasmático $(4,4,6)$.

Cuando la célula CD34+ de origen mieloide inicia la maduración hacia la línea granulocítica, monocítica y eritroide, va perdiendo progresivamente la molécula CD34 en su superficie e incrementa los niveles de expresión de CD45, CD13, CD33, disminuyendo la reactividad para CD117 $(4,6)$ y a medida que estas células se comprometen hacia estos linajes van expresando de forma dinámica marcadores específicos de los mismos. Precisamente el incremento en los niveles de expresión de MPO se asocia con la maduración hacia neutrófilo, la adquisición de CD64 y/ó CD14 se observa en la diferenciación hacia línea monocítica, y la pérdida de expresión de CD45, en conjunto con la fuerte positividad para CD71 y la adquisición de glicoforina A (CD235a) y CD36 definen la maduración hacia el linaje eritroide $(4,6)$.

Se han descrito diferentes combinaciones de anticuerpos para evaluar la maduración hacia neutrófilo, incluyendo marcadores como CD11b y CD16 y la combinación de CD13 y CD11b $(3,4)$. En el presente trabajo la maduración desde promielocito hasta neutrófilo se evaluó empleando la combinación CD13/CD11b, donde los promielocitos son característicamente CD13++/CD11b-, los mielocitos CD13+ débil/CD11b-, los metamielocitos CD13-/CD11b+ y los neutrófilos CD13+/CD11b++ (4). Otros marcadores expresados en esta línea desde el estadio de promielocito son MPO, CD15, CD33, y CD16 los cuales se mantienen hasta el estadio de neutrófilo maduro (4).

El linaje monocítico proviene del progenitor mieloide CD34+/CD117+, y a medida que ocurre la diferenciación a promonocito y monocito se observan variaciones fenotípicas que incluyen aumento en la expresión de CD45, CD64 y CD33, disminución de los niveles de expresión de CD15 y adquisición del marcador CD14 en monocitos. Por otra parte, las células dendríticas derivadas de monocito expresan altos niveles de CD16 (4).

Las células de linaje eritroide se caracterizan fenotípicamente por la pérdida secuencial del marcador CD45, desde los proeritroblastos hasta el eritrocito maduro (4). Adicionalmente, durante la diferenciación a eritrocito estas células adquieren en su superficie el receptor de transferrina CD71 en conjunto con el CD235a (glicoforina A), hasta que el eritrocito maduro pierde el CD71 conservando el marcador CD235a (4).

Las células dendríticas (DCs) pueden diferenciarse a partir de un progenitor mieloide CD34+ (la gran mayoría), o a partir de un precursor linfoide (DCs plasmacitoides). En la actualidad diferentes estudios han ampliado la información disponible en relación con las diferencias inmunofenotípicas entre las distintas subpoblaciones de DCs de MO estableciendo que las DCs mieloides son CD11 $\mathrm{c}^{++} / \mathrm{CD} 33^{+++} / \mathrm{CD} 16 / \mathrm{CD} 123^{+}$, las DCs derivadas del monocito son $\mathrm{CD} 11 \mathrm{c}^{+} / \mathrm{CD} 33^{++} / \mathrm{CD} 16^{+} / \mathrm{CD} 123^{+}$, mientras que las DCs plasmocitoides son $\mathrm{CD} 11 \mathrm{c}^{+} / \mathrm{CD} 33^{-}$ ${ }^{\prime+} / \mathrm{CD} 16 / \mathrm{CD} 123^{++}$. En conjunto estas células muestran expresión intensa de HLA-DR con positividad variable para marcadores mielomonocíticos, moléculas de adhesión (CD11a, CD18), receptores para complemento (CD21, CD35, CD23 y receptores de quemoquinas (CXCR4, CXCR3) entre otros $(18 ; 19)$.

Los mastocitos corresponden a otra subpoblación celular derivada de precursores mieloides CD34+/CD117+/ $\mathrm{CD} 13+$, con una baja frecuencia reportada a nivel de $\mathrm{MO}$ normal tal como lo observamos en el presente estudio . Diferentes estudios han mostrado que los mastocitos expresan dos marcadores fenotípicos con alta intensidad: el antígeno CD117 y el receptor Fc de la IgE (FceRI), (21). Sin embargo, estas moléculas no son específicas de este subgrupo celular, ya que el CD117 es positivo en progenitores mieloides de $\mathrm{MO}$ y en células de origen no hematopoyético (p.ej. melanocitos) y el FceRI es además positivo en basófilos $(13,21)$. Otras moléculas expresadas en mastocitos son CD45, CD71, CD44, CD13, CD11b, y 
CD40 entre otros (21). Adicionalmente, los basófilos que también constituyen una población de baja frecuencia $(0,2 \% \pm 0,2 \%$ de la celularidad total $)$, se pueden distinguir fenotípicamente por la expresión de CD123 en ausencia de HLA-DR, y expresión de otros marcadores de linaje mieloide como CD13 y CD11b(6), tal como lo reportamos en el presente estudio.

Por otra parte, la caracterización inmunofenotípica de los SMD y las LMA por CMF es de gran utilidad en la identificación y recuento de blastos $(3,14)$ y en la evaluación de fenotipos aberrantes que incluyen asincronismos madurativos, infidelidad de linaje, y sobre-expresión e infra-expresión antigénica (3). Fenotipos altamente asociados con la presencia de anomalías genéticas recurrentes asociadas a estas entidades (22), (ej. -t $\mathrm{t}(15 ; 17)$ en leucemia promielocítica aguda con promielocitos aberrantes CD15-/+ débil, CD33++; inv(16)/t(16;16) relacionada con expresión fuerte de MPO, CD2-/+ débil y presencia de monocitos aberrantes; y los casos con $\mathrm{t}(8 ; 21)$ con expresión de CD19 y CD56, mientras que los casos con anomalías a nivel de $11 \mathrm{q} 23$ se asocian a fenotipo CD56+, 7,1-/+, CD2-/+ y CD19-/+ débil (3). Además, se observan patrones alterados de tamaño y complejidad y alteraciones en la distribución numérica de los mieloblastos, linfoblastos y otras subpoblaciones celulares $(3,14)$.

Dentro de las aberraciones fenotípicas reportadas en mieloblastos de SMD se incluyen variaciones en la intensidad de los marcadores CD45, CD34, HLA-DR y CD117, con expresión aberrante de CD15, CD36, CD7 y CD11b (14). En la línea granulocítica se reportan anormalidades en la granularidad (23) con sobre-expresión e infra-expresión de los antígenos CD45, CD13, CD33, CD11b, CD16 y CD64 con pérdida de expresión de CD10 y expresión aberrante de CD34 y CD14 . En el linaje monocítico se ha reportado sobre-expresión e infra-expresión de CD13, CD33, patrones anormales en la expresión de CD11b, HLA-DR, CD14, CD64 y CD36 (14). En la línea eritroide se reportan anormalidades en la expresión de CD45, CD71, CD235a y CD117. Aberraciones fenotípicas en los mastocitos son observadas con alta frecuencia en el caso de las mastocitosis sistémicas y las leucemias de mastocitos, en las que se observa ganancia de marcadores de linaje linfoide CD2 y CD25 (en más del 90\% de los casos) en conjunto con CD117, por lo que constituyen marcadores muy útiles para diferenciar mastocitos normales de los mastocitos aberrantes en estas enfermedades (21). En conjunto en los SMD y en la mayoría de linajes se observa la expresión de marcadores de infidelidad de línea como TdT, CD56, CD7, CD2, CD5 y CD19 (6;14). Por lo que la identificación de fenotipos aberrantes en el momento del diagnóstico representa una herramienta de gran utilidad en el seguimiento de la enfermedad post-tratamiento (enfermedad mínima residual) (9).
En el presente estudio, la determinación de los valores absolutos y relativos y los resultados del inmunofenotipo, permitieron la identificación de las distintas poblaciones leucocitarias normales en MO incluyendo poblaciones que se encuentran en muy baja frecuencia (p.ej. mastocitos, basófilos, células dendríticas y células stem hematopoyéticas). Estos resultados podrán ser utilizados por los laboratorios de Citometría como modelo para establecer parámetros de referencia en el análisis fenotípico de LMA y SMD y como parte del control de calidad de rutina que se debe aplicar en estos laboratorios.

\section{Agradecimientos}

Los autores agradecen al Servicio de Ortopedia Hospital Universitario San Ignacio.

\section{Financiación}

Este estudio fue financiado por el Hospital Universitario San Ignacio.

\section{Conflicto de intereses}

Los autores declaran que no existen conflictos de intereses relacionados con este trabajo.

\section{Referencias}

1. Chitteti BR, Cheng YH, Poteat B, RodriguezRodriguez S, Goebel WS, Carlesso N, Kacena MA, Srour EF. Impact of interactions of cellular components of the bone marrow microenvironment on hematopoietic stem and progenitor cell function. Blood 2010; 115: 3239-3248.

2. Kiel MJ, Morrison SJ. Uncertainty in the niches that maintain haematopoietic stem cells. Nature Reviews Immunology 2008; 8: 290-301.

3. Orfao A, Ortuno F, De Santiago M, Lopez A, San Miguel J. Immunophenotyping of acute leukemias and myelodysplastic syndromes. Cytometry A 2004; 58: 62-71.

4 van Lochem EG, van dV, V, Wind HK, te Marvelde JG, Westerdaal NA, van Dongen JJ. Immunophenotypic differentiation patterns of normal hematopoiesis in human bone marrow: reference patterns for age-related changes and disease-induced shifts. Cytometry B Clinical Cytometry 2004; 60: 1-13. 
5 Craig FE, Foon KA. Flow cytometric immunophenotyping for hematologic neoplasms. Blood 2008; 111: 3941-3967.

6 Matarraz S, Lopez A, Barrena S, Fernandez C, Jensen E, Flores, Barcena P, Rasillo A, Sayagues JM, Sanchez ML, Hernandez-Campo P, Hernandez Rivas JM, Salvador C, Fernandez-Mosteirin N, Giralt M, Perdiguer L, Orfao A. The immunophenotype of different immature, myeloid and B-cell lineage-committed CD34+ hematopoietic cells allows discrimination between normal/reactive and myelodysplastic syndrome precursors. Leukemia 2008; 22: 1175-1183.

7 Quijano S, Lopez A, Rasillo AI, Sayagues JM, Barrena S, Sanchez ML, Teodosio C, Giraldo P, Giralt M, Perez MC, Romero M, Perdiguer L, Orfao A. Impact of trisomy $12, \operatorname{del}(13 q), \operatorname{del}(17 p)$ and $\operatorname{del}(11 q)$ on the immunophenotype, DNA ploidy status and proliferative rate of leukemic B-cells in chronic lymphocytic leukemia. Cytometry B Clinical Cytometry 2008; 74: 139-149.

8 Matarraz S, Lopez A, Barrena S, Fernandez C, Jensen E, Flores-Montero J, Rasillo A, Sayagues JM, Sanchez ML, Barcena P, Hernandez-Rivas JM, Salvador C, Fernandez-Mosteirin N, Giralt M, Perdiguer L, Laranjeira P, Paiva A, Orfao A. Bone marrow cells from myelodysplastic syndromes show altered immunophenotypic profiles that may contribute to the diagnosis and prognostic stratification of the disease: A pilot study on a series of 56 patients. Cytometry B Clinical Cytometry 2010; 78: 154-178.

9 Vidriales MB, San-Miguel JF, Orfao A, Coustan-Smith E, Campana D. Minimal residual disease monitoring by flow cytometry. Best Practice \& Research Clinical Haematology 2003; 16: 599-612.

10 Barrena S, Almeida J, Yunta M, Lopez A, FernandezMosteirin N, Giralt M, Romero M, Perdiguer L, Delgado M, Orfao A, Lazp PA. Aberrant expression of tetraspanin molecules in B-cell chronic lymphoproliferative disorders and its correlation with normal Bcell maturation. Leukemia 2005; 19: 1376-1383.

11 Kraan J, Gratama JW, Haioun C, Orfao A, Plonquet A, Porwit A, Quijano S, Stetler-Stevenson M, Subira D, Wilson W. Flow cytometric immunophenotyping of cerebrospinal fluid. Current Protocols in Cytometry 2008; Chapter 6: Unit 6.25.

12 Kawamoto H, Wada H, Katsura Y. A revised scheme for developmental pathways of hematopoietic cells: the myeloid-based model. International Immunology 2010; 22: 65-70.
13 Ruiz-Arguelles A, Rivadeneyra-Espinoza L, Duque RE, Orfao A. Report on the second Latin American consensus conference for flow cytometric immunophenotyping of hematological malignancies. Cytometry B Clinical Cytometry 2006; 70: 39-44.

14 van de Loosdrecht AA, Alhan C, Bene MC, la Porta MG, Drager AM, Feuillard J, Font P, Germing U, Haase D, Homburg CH, Ireland R, Jansen JH, Kern W, Malcovati L, Te Marvelde JG, Mufti GJ, Ogata K, Orfao A, Ossenkoppele GJ, Porwit A, Preijers FW, Richards SJ, Schuurhuis GJ, Subira D, Valent P, van der Velden VH, Vyas P, Westra AH, de Witte TM, Wells DA, Loken MR, Westers TM. Standardization of flow cytometry in myelodysplastic syndromes: report from the first European LeukemiaNet working conference on flow cytometry in myelodysplastic syndromes. Haematologica 2009; 94: 1124-1134.

15 Westers TM, Alhan C, Chamuleau ME, van d, V, Eeltink C, Ossenkoppele GJ, van de Loosdrecht AA. Aberrant immunophenotype of blasts in myelodysplastic syndromes is a clinically relevant biomarker in predicting response to growth factor treatment. Blood 2010; 115: 1779-1784.

16 Lucio P, Parreira A, van den Beemd MW, van Lochem EG, van Wering ER, Baars E, Porwit-MacDonald A, Biorklund E, Gaipa G, Biondi A, Orfao A, Janossy G, van Dongen JJ, San Miguel JF. Flow cytometric analysis of normal B cell differentiation: a frame of reference for the detection of minimal residual disease in precursor-B-ALL. Leukemia 1999; 13: 419-427.

17 Ciudad J, Orfao A, Vidriales B, Macedo A, Martinez A, González M, Lopez-Berges MC, Valverde B, San Miguel JF. Immunophenotypic analysis of CD19+ precursors in normal human adult bone marrow: implications for minimal residual disease detection. Haematologica 1998; 83: 1069-1075.

18 Orfao A. Neoplasias of dentritic cells: are they the counterpart of one or more cell lineages? Laboratory Hematology 2004; 10: 171.

19 Martin-Martin L, Almeida J, Hernandez-Campo PM, Sanchez ML, Lecrevisse Q, Orfao A. Immunophenotypical, morphologic, and functional characterization of maturation-associated plasmacytoid dendritic cell subsets in normal adult human bone marrow. Transfusion 2009; 49: 1692-1708.

20 Escribano L, Díaz-Agustin B, Lopez A, Nunez LR, Garcia-Montero A, Almeida J, Prados A, Angulo M, Herrero S, Orfao A. Immunophenotypic analysis of mast cells in mastocytosis: When and how to do it. 
Proposals of the Spanish Network on Mastocytosis (REMA). Cytometry B Clinical Cytometry 2004; 58: $1-8$.

21 Escribano L, Garcia Montero AC, Nunez R, Orfao A. Flow cytometric analysis of normal and neoplastic mast cells: role in diagnosis and follow-up of mast cell disease. Immunology and Allergy Clinics of North America 2006; 26: 535-547.
22 Orfao A, Ortuno F, de SM, Lopez A, San MJ. Immunophenotyping of acute leukemias and myelodysplastic syndromes. Cytometry A 2004; 58: 62-71.

23 Stetler-Stevenson M, Arthur DC, Jabbour N, Xie XY, Molldrem J, Barrett AJ, Venzon D, Rick ME. Diagnostic utility of flow cytometric immunophenotyping in myelodysplastic syndrome. Blood 2001; 98: 979-987. 